\title{
The effectiveness of a squash eyewear promotion strategy
}

\author{
R Eime, C Finch, R Wolfe, N Owen, C McCarty
}

Br J Sports Med 2005;39:681-685. doi: 10.1136/bjsm.2005.018366

See end of article for authors' affiliations .....................

Correspondence to: Professor Caroline Finch, University of New South Wales, NSW Injury Risk Management Research Centre, NSW, Australia; c.finch@unsw.edu.au

Accepted 6 March 2005

\begin{abstract}
Objective: To evaluate the protective eyewear promotion (PEP) project, which was a comprehensive educational strategy to increase the use of appropriate protective eyewear by squash players. Methods: An ecological study design was used. Four squash venues in one playing association were randomly chosen to receive PEP and four in another association maintained usual practice and hence formed a control group. The primary evaluation measurements were surveys of cross sectional samples of players carried out before and after the intervention. The surveys investigated players' knowledge, behaviours, and attitudes associated with the use of protective eyewear. The survey carried out after the intervention also determined players' exposure to PEP. Univariate and multivariate analyses were undertaken to describe differences at PEP venues from pre- to post-intervention and to compare these with the control venues.

Results: The PEP players had 2.4 times the odds (95\% confidence interval, 1.3 to 4.2 ) of wearing appropriate eyewear compared with control group players post-intervention, relative to the groups' preintervention baselines. Components of PEP, such as stickers and posters and the availability and prominent positioning of the project eyewear, were found to contribute to players adopting favourable eyewear behaviours.

Conclusions: Components of the PEP intervention were shown to be effective. The true success will be the sustainability and dissemination of the project, favourable eyewear behaviours, and evidence of the prevention of eye injuries long into the future.
\end{abstract}

A ssociated with participation in sport and physical activity is a risk of sustaining an injury. ${ }^{12}$ Nonetheless, sports injuries are not inevitable and many injuries can be prevented. Most sports injury research to date has focused solely on injury surveillance activities. ${ }^{3}$ Although data gathered from surveillance systems have been shown to be useful for guiding sports injury prevention strategies, ${ }^{245}$ surveillance alone does not prevent injuries from occurring.

In order to prevent sports injuries, both the extent of the problem and the preceding aetiology and causal mechanisms need to be established. ${ }^{2}$ These steps are essential before the design and implementation of any prevention strategy. We have previously applied this framework for the prevention of eye injuries in squash. The specific injury incidence and severity eye injuries in squash, as well as their mechanisms, have been identified.$^{6-8}$ A rate of 19 eye injuries per 100000 squash players has been calculated from emergency departments and hospitals throughout Victoria, Australia. ${ }^{8}$

It has been long established that squash eye injuries can be prevented by the use of appropriate eyewear-that is, Standards Approved protective eyewear of polycarbonate lenses. ${ }^{9-14}$ However, fewer than $10 \%$ of Australian adult players protect their eyes adequately. ${ }^{6}$

Our aim in this study was to evaluate the implementation of a health education and eyewear promotion strategy, named the protective eyewear promotion (PEP), aimed specifically at squash players. The design of this eye injury prevention strategy has been described in detail previously. ${ }^{15}$ In summary, behaviour change principles, in combination with player survey results, were applied to develop a comprehensive strategy to increase the use of appropriate eyewear in squash. The main components of PEP involved informing and educating both players and squash venue operators of the risk of eye injury and of appropriate protective eyewear, as well as assisting with the availability of the eyewear and offering incentives for players to use it.
This involved the provision of eyewear for players to try out and purchase, as well as the display of educational pamphlets and task specific posters and stickers at suitable venues such as the registration desk, near the squash courts, and in the changing rooms.

In this paper we report a formal evaluation of PEP. The aim of this controlled evaluation was to compare outcomes such as players' eyewear behaviour characteristics before and after the intervention to see if there was any benefit associated with PEP.

\section{METHODS}

The methods and procedures for this study were approved by the standing committee on ethics in research involving humans, Monash University.

An ecological study design was used. Two squash associations of different geographical locations, one in the northwest region of Melbourne and the other in the southeast region, were randomly allocated to one of two groups: PEP (to receive the intervention) and control (without the intervention). The geographical separation of the two groups minimised contamination of players between them. Four PEP and four control venues were randomly selected from the list of public squash venues in the two separate playing associations. The managers of the eight venues were contacted and all agreed to be involved in the project.

Independent samples of squash players were surveyed before and after the intervention to gather information on player profiles (age, sex, playing history, and so on) as well as their knowledge of and attitudes towards protective eyewear. The post-intervention survey also investigated players' knowledge and exposure to the PEP. The sampling procedures for the two player surveys were the same. Data collection sessions were randomly chosen during peak playing times at each of the venues. Each adult player

Abbreviations: PEP, protective eyewear promotion 
present at the selected venues during the sampling times was approached to complete an anonymous survey. Players' squash participation was not interrupted. Players not wishing to participate and unreturned surveys were noted as nonresponses. No player completed more than one survey in either the pre-intervention or the post-intervention group, and these surveys were generally not administered to the same players.

The project provision of eyewear and educational materials was delivered and set up at the PEP squash venues. These venues were visited weekly for monitoring purposes. The PEP venue managers completed record forms to report the borrowing/loan and sales of eyewear during the trial. At the end of the four month project trial period, the PEP components remained in place at the venues, and the venues continued to conduct the PEP eye safety practices.

Usual safety practices were undertaken at the control venues during the project period. The managers of these venues were informed that upon completion of the project they would, if they wished, be provided with the promotional information and materials supplied to the PEP venues.

Self reported appropriate eyewear was defined as Standards Approved polycarbonate eyewear. ${ }^{16}$ All other types of eyewear were considered inappropriate as they do not provide adequate eye protection. For each survey participant, a total attitudinal score was calculated by summing their responses to 10 Likert scale safety statements. A lower total score indicated a more favourable safety attitude. Subtle wording differences between the 2002 and 2003 questionnaires may account for some changes observed pre- and postintervention. For example, we analysed the response "Ever worn protective eyewear for squash" where in 2002 the question was "Do you wear protective eyewear when playing?" and in 2003 the question was "Have you ever worn protective eyewear when playing?".

The number of venues was determined through power calculations based on expected rates of appropriate and inappropriate protective eyewear use, attitudes towards protective eyewear use, and knowledge of appropriate protective eyewear. To detect an increase in appropriate eyewear use at PEP venues from 7\% pre-intervention to $15 \%$ post-intervention, and a decrease in inappropriate eyewear the use from $19 \%$ to $9 \%$, we determined that a sample size of 189 players at PEP and control venues would be required for $80 \%$ power. Based on previous samples, an estimated mean of 30 players participated on a typical competition night at each venue, ${ }^{17}$ so each of four PEP and four control venues was visited three times. No adjustment was made for the clustering of players by squash venue or data collection session in these calculations, but we determined intracluster correlations and design effects ${ }^{18}$ to assess whether this simplification led to a reduction in power.
Where data were available only from post-intervention questionnaires, we compared responses between players at PEP and control venues. Where relevant responses were available from both pre- and post-intervention questionnaires, we analysed the difference between them, specifically whether these differences varied between PEP and control venues. We used a linear regression model for total attitude score, and logistic regression models for all other responses. We estimated model parameters using maximum likelihood with person, rather than venue, as the unit of analysis and calculated robust standard errors (SE) using the information sandwich formula to take account of the clustering of players by squash venue. ${ }^{19}$

Multivariate regression models were used to adjust for potential player specific confounders. Where sufficient data was available, we adjusted for years played, grade of competition, hours usually played per week, and sex. Adjustments were made for the analysis of total attitude score which had 10 responses per model parameter, and the analysis of "ever worn protective eyewear for squash" (which had at least 10 positive and 10 negative responses per parameter). For all other responses, we adjusted for years played and hours usually played per week (assuming doseresponse relations across the four categories) and sex. Grade of play was not included because there was no evidence of a difference between PEP and control venues in the changing distribution of grades.

\section{RESULTS}

At the PEP venues, 266 players completed the survey before the intervention (response rate 93\%), and 379 after the intervention (response rate 97\%). At the control venues, 170 players were surveyed before the intervention (response rate $89 \%)$ and 232 after the intervention.

Table 1 shows the median age and sex of survey participants. The difference in median age across the four groups was not significant $(p=0.35)$. Before the intervention, the proportions of men and women between the two groups were similar (PEP 65.9\% male $v$ control $60.2 \%$ male, $95 \%$ confidence interval (CI) for difference, -0.07 to 0.11 ). However, after the intervention, a significant difference in the sex ratio appeared (PEP 71.9\% male $v$ control $80.3 \%$ male, 95\% CI for difference, -0.16 to -0.01 ).

Table 1 also provides a summary of the playing standard of participants. The majority of players participated in competition and were high grade players (State grade, grade 4). Some factors were imbalanced across the samples and we adjusted for these in multivariate analyses.

There was no difference between PEP and control groups in the pre- to post-intervention change in the proportion of players reportedly wearing protective eyewear (univariate odds ratio $(\mathrm{OR})=0.77(95 \% \mathrm{CI}, 0.41$ to 1.45$)$ ). The conclusion

Table 1 Comparison of demographics and standard of play in the protective eyewear promotion (PEP) and control groups before and after the intervention

\begin{tabular}{|c|c|c|c|c|}
\hline & \multicolumn{2}{|l|}{ Pre-intervention } & \multicolumn{2}{|l|}{ Post-intervention } \\
\hline & PEP $2002(n=266)$ & Control $2002(n=146)^{*}$ & PEP $2003(n=360)^{*}$ & Control $2003(n=220)^{*}$ \\
\hline Median age (years) & 38 & 39 & 39 & 37 \\
\hline Sex (\% male) & 66 & 60 & 72 & 80 \\
\hline \multicolumn{5}{|l|}{ Highest grade } \\
\hline Grade 1-4 & $45.1 \%(39.1$ to 51.1$)$ & $51.4 \%(43.3$ to 59.5$)$ & $35.3 \%(30.4$ to 40.2$)$ & $39.5 \%(33.0$ to 46.0$)$ \\
\hline Grade 5> & $25.2 \%(20.0$ to 30.4$)$ & $32.2 \%(24.6$ to 39.8$)$ & $17.2 \%(13.3$ to 21.1$)$ & $8.2 \%(4.6$ to 11.8$)$ \\
\hline Social-recreational & $15.0 \%(10.7$ to 19.3$)$ & $11.6 \%(6.4$ to 16.8$)$ & $29.4 \%(24.7$ to 34.1$)$ & $31.8 \%(25.6$ to 38.0$)$ \\
\hline State grade & $14.6 \%(10.4$ to 18.8$)$ & $4.8 \%(1.3$ to 8.3$)$ & $18 . \%(14.1$ to 22.1$)$ & $20.5 \%(15.2$ to 25.8$)$ \\
\hline
\end{tabular}

Values are percentages with $95 \%$ confidence intervals.

*Control 2002: 24 missing values; PEP 2003: 19 missing values; control 2003: 12 missing values. 
Table 2 Differences in eyewear use for protective eyewear promotion (PEP) and control groups

\begin{tabular}{|c|c|c|c|c|}
\hline & \multirow[b]{2}{*}{ No eyewear } & \multicolumn{2}{|c|}{ Used eyewear } & \multirow[b]{2}{*}{$\chi^{2} 2002$ v 2003} \\
\hline & & $\begin{array}{l}\text { Appropriate } \\
\text { eyewear }\end{array}$ & $\begin{array}{l}\text { Inappropriate } \\
\text { eyewear }\end{array}$ & \\
\hline PEP $2002^{*}$ & $216(82.4 \%)$ & $21(8.0 \%)$ & $25(9.5 \%)$ & \\
\hline PEP 2003* & 275 (78.8\%) & $48(13.8 \%)$ & $26(7.4 \%)$ & PEP $p=0.67$ \\
\hline Control 2002* & 147 (87.0\%) & $12(7.1 \%)$ & $10(5.9 \%)$ & \\
\hline Control 2003* & $173(82.8 \%)$ & $20(9.6 \%)$ & $16(7.7 \%)$ & Control $p=0.53$ \\
\hline
\end{tabular}

on PEP $v$ control differences was unchanged by multivariate analysis. However, this analysis included all types of eyewear worn by any player believing they were protecting their eyes through using that eyewear.

Table 2 summarises the pre to post differences in the type of eyewear worn for the PEP and control groups separately. In the PEP group, the proportion of players using appropriate eyewear increased, while the use of inappropriate eyewear decreased from pre- to post-intervention. In the control group, the use of appropriate eyewear increased slightly, as did the use of inappropriate eyewear.

The PEP players had 2.4 times greater odds (univariate OR; $95 \% \mathrm{CI}, 1.3$ to 4.2 ) than control players of wearing appropriate eyewear (rather than all other types of eyewear) compared with control players, over and above the PEP $v$ control difference before the intervention. This finding was partly explained by adjusting for confounders (multivariate $\mathrm{OR}=1.8(95 \% \mathrm{CI}, 0.9$ to 3.5$))$.

In the post-intervention survey, players who reported wearing protective eyewear were asked to report when they first started using it. A response of "this year" would indicate that they began using it during the PEP initiative, because PEP ran from January to April inclusive. Players at PEP venues were 2.1 times more likely than control players to begin wearing protective eyewear "this year" $(\mathrm{p}=0.04$; 95\% CI, 1.1 to 4.2 ), and this finding was not explained by confounding with other factors (multivariate OR $=3.0(95 \%$ CI, 1.1 to 8.2), $\mathrm{p}=0.03$ ).

There was one significant pre- to post-intervention difference between PEP and control venues in the change in players' beliefs about which eyewear provided adequate protection (table 3 ). The PEP group had a greater increase in knowledge that open eye guards do not provide adequate protection (multivariate analysis, $\mathrm{p}=0.05$ ). The effect of the cluster randomised design - that is, the clustering of players by squash venues-was minimal: for the items of knowledge analyses in table 3, the design effects and intracluster correlations, respectively, were 1.15 and 0.0025 for "polycarbonate lenses", 1.09 and 0.0016 for open eye guards, 1.08 and 0.0013 for don't know, 1.10 and 0.0017 for industrial eyewear, 1.66 and 0.0111 for prescription glasses, and 0.33 and -0.0114 for contact lenses.

The above analyses were carried out on an intervention allocation basis and we investigated group crossover and the extent of exposure to PEP. Nearly all the players surveyed at a PEP venue were either members of a PEP venue $(66.0 \%)$ or neither members of a PEP venue nor of a control venue $(33.7 \%)$. This trend was similar for those players surveyed at a control venue: $67.1 \%$ were members of a control venue and $31.1 \%$ were neither members of a PEP venue nor of a control venue. The number of times each player visited a PEP venue is presented in table 4 . The PEP players surveyed after the intervention had made more visits to a PEP venue than control players.

After the intervention, all surveyed players who had attended a PEP venue at least once during the intervention period were asked whether or not they had noticed any eyewear promotion. Most players at both PEP (65\%) and control venues $(58 \%)$ who had attended a PEP venue during the project remembered seeing PEP material. Of the players

Table 3 Change in knowledge about appropriate protective eyewear: PEP players $v$ control players, pre- $v$ post-intervention

\begin{tabular}{|c|c|c|}
\hline Eyewear thought to be protective & Univariate analysis & Multivariate analysis \\
\hline $\begin{array}{l}\text { Polycarbonate lens } \\
\text { p Value }\end{array}$ & $\begin{array}{l}0.77 \text { (0.45 to } 1.35) \\
0.37\end{array}$ & $\begin{array}{l}0.74 \text { (0.39 to } 1.36) \\
0.32\end{array}$ \\
\hline $\begin{array}{l}\text { Open eye guards } \\
\mathrm{p} \text { Value }\end{array}$ & $\begin{array}{l}0.56 \text { (0.29 to } 1.07) \\
0.08\end{array}$ & $\begin{array}{l}0.51(0.26 \text { to } 1.1) \\
0.05\end{array}$ \\
\hline $\begin{array}{c}\text { Don't know } \\
\text { p Value }\end{array}$ & $\begin{array}{l}1.57(0.91 \text { to } 2.7) \\
0.10\end{array}$ & $\begin{array}{l}1.72 \text { (0.89 to } 3.30) \\
0.10\end{array}$ \\
\hline $\begin{array}{l}\text { Industrial eyewear } \\
\text { p Value }\end{array}$ & $\begin{array}{l}0.95 \text { (0.45 to } 1.97) \\
0.88\end{array}$ & $\begin{array}{l}1.00 \text { (0.46 to } 2.21) \\
0.99\end{array}$ \\
\hline $\begin{array}{l}\text { Prescription glasses } \\
\text { p Value }\end{array}$ & $\begin{array}{l}0.71 \text { (0.20 to } 2.50) \\
0.59\end{array}$ & $\begin{array}{l}0.70 \text { (0.18 to } 2.71) \\
0.61\end{array}$ \\
\hline $\begin{array}{l}\text { Contact lenses } \\
\mathrm{p} \text { Value }\end{array}$ & $\begin{array}{l}0.92(0.33 \text { to } 2.59) \\
0.88\end{array}$ & $\begin{array}{l}0.89 \text { (0.30 to } 2.66) \\
0.84\end{array}$ \\
\hline
\end{tabular}


Table 4 Frequency of visits to players' most visited PEP venue during the intervention period

\begin{tabular}{lll}
\hline $\begin{array}{l}\text { Number of visits to } \\
\text { a PEP venue }\end{array}$ & $\begin{array}{l}\text { PEP group } \\
(\mathbf{n}=\mathbf{3 7 7})^{*}\end{array}$ & $\begin{array}{l}\text { Control group } \\
(\mathbf{n}=\mathbf{2 2 3})^{*}\end{array}$ \\
\hline None & $2.1 \%$ & $73.1 \%$ \\
Once & $5.8 \%$ & $6.3 \%$ \\
$2-5$ times & $21.8 \%$ & $11.2 \%$ \\
$6-10$ times & $10.3 \%$ & $3.6 \%$ \\
$10+$ times & $60.0 \%$ & $5.8 \%$
\end{tabular}

*PEP, 2 missing values; control, 9 missing values.

who had visited a PEP venue only once, 54\% remembered PEP material and half ( $52 \%$ ) of players who had visited a PEP venue two to 10 times had noticed the promotion. Players who had visited a particular PEP venue more than 10 times were significantly more likely to have noticed the promotion $(76 \%)$ than those who had visited less than 10 times $(\mathrm{p}<0.001)$.

The components of the promotion that were noticed are summarised in table 5, according to the maximum number of times a player had visited a PEP venue. The more visits that players had made to PEP venues, the more likely they were to remember components of the PEP promotion. The single most commonly remembered PEP message (by 40\% of exposed players) was the slogan on the sticker: "Protective Eyewear, Let's Get It On".

The attitudinal scores were approximately normally distributed. Overall, the responses to the attitudinal statements displayed favouritism towards protective eyewear safety. However, there was no evidence of a difference between the PEP and control groups in the mean attitude score change from pre- to post-intervention (multivariate difference in mean score change $=0.9(95 \% \mathrm{CI},-0.2$ to 2.0$))$.

In a post-PEP review, all control venue managers stated that they had appropriate protective eyewear available for players to purchase. During the four month trial, PEP venues recorded 65 sales of project eyewear and 161 occasions of players borrowing eyewear. The control venues collectively had only five sales and no borrowings over the same period.

\section{DISCUSSION}

It is well supported that, collectively, attitudes towards and knowledge about safety protection can substantially influence safety behaviours. ${ }^{20-22}$ Strategies to achieve behaviour change need to be based on ecological behavioural models. ${ }^{23}$ Such models identify intrapersonal factors, sociocultural factors, policies, and physical environments as levels of influence on health related behaviours. ${ }^{23}$ Importantly, they recognise that many factors combine to influence an individual's behavioural choices. ${ }^{22}$

Before this evaluation, the amount of exposure needed for players to notice or be influenced by an education and programme promotion such as PEP was unknown. In this instance, it would seem that visiting a PEP venue 10 times or more is significantly correlated to recognising at least one component of PEP, but not necessarily to a specific eyewear behaviour change. It was encouraging that even the proportion of players who had only visited a PEP venue once and had noticed PEP material was high. Results showed many players who were exposed to PEP did adopt favourable eyewear behaviour during the four month period.

An important aspect in any controlled evaluation is crosscontamination of individuals in control and intervention groups. In the context of an ecological design, this is difficult to avoid. Only a small proportion of players surveyed at a PEP venue were a member of a control venue, and vice versa. The random allocation of PEP and control venues within two different playing associations helped to minimise contamination of study groups.

As expected, there were very few differences in group demographics, playing habits, and standards in the two survey years. Those factors found to vary were controlled for in the analyses. This shows that the two groups were relatively well balanced at baseline.

At first sight, it would seem that overall the PEP players had less favourable eyewear behaviour than control players after the intervention compared with before. However, this was measured on the basis of self reported eyewear use of any type. More control players "believed" they were wearing protective eyewear when in fact they were not wearing adequate protection. When assessing only appropriate protective eyewear use, the PEP players were significantly more likely to wear appropriate eyewear than other types of eyewear. This suggests a positive behaviour change in the population of players exposed to PEP which was likely to have been associated with the intervention. Analysis of when players started to wear protective eyewear showed that PEP players were influenced by PEP rather than by external factors.

Fewer PEP players than controls reported knowing that polycarbonate lens eyewear is the appropriate form of eye protection. This finding could be a limitation or error in the survey design. The difference did not seem to be reflected in their behaviours, because significantly more PEP players than controls wore appropriate eyewear after the intervention compared with before. The knowledge specific messages on the posters stated "wear Approved Protective eyewear" and listed the brands. They did not specifically mention polycarbonate lenses. The high frequency of players noticing the promotional posters was a positive finding. Open eye guards do not provide adequate protection, ${ }^{24}$ and PEP players were more likely than the control group to know this after the intervention.

The study had some limitations. The number of surveyed players was lower than required for $90 \%$ power; nonetheless, the statistical power was still more than $70 \%$. Importantly, the response rates before and after the intervention were

Table 5 Player recall of intervention components in relation to the number of visits they made to the PEP venues

\begin{tabular}{llll}
\hline Yes, noticed component of promotion* & $<2$ visits & 2-10 visits & 10+ visits \\
\hline Posters & $21(77.8 \%)$ & $61(79.2 \%)$ & $144(81.8 \%)$ \\
Pamphlets & $3(11.1 \%)$ & $6(7.8 \%)$ & $49(27.8 \%)$ \\
Stickers & $8(29.6 \%)$ & $12(15.6 \%)$ & $60(34.1 \%)$ \\
Eyewear available to borrow & $4(14.8 \%)$ & $13(16.9 \%)$ & $58(33.0 \%)$ \\
Cheaper eyewear & 0 & $7(9.1 \%)$ & $20(7.1 \%)$ \\
Incentive to try and purchase eyewear & 0 & $7(9.1 \%)$ & $18(10.1 \%)$ \\
\hline
\end{tabular}

Values are $\mathrm{n}(\%)$.

*Players could respond with more that one option. 


\section{What is already known on this topic}

There is a risk of serious eye injury during sport. The use of appropriate protective eyewear has been shown to prevent these injuries. However, fewer than $10 \%$ of adult squash players voluntarily wear appropriate protective eyewear in Australia.

\section{What this study adds}

Ecological models of behaviour change can be used to develop sports safety strategies incorporating protective equipment. A specifically targeted squash eye safety promotion strategy is effective in educating players about squash eye injury risk and for encouraging more players to wear protective eyewear.

high. The personal approach to each survey participant, while costly in time, contributed to the high response rate.

This study did not follow up individual players; rather, independent samples were used before and after the intervention. To achieve follow up of individuals would have been logistically difficult and costly. It would seem from the low contamination of players between the project groups that this evaluation was robust enough to detect a difference when one was present. Our design is common in community trials where a community (corresponding to a squash venue in our study) is followed up rather than individuals within the community.

The results showed no significant difference in players' eye safety attitudes after PEP. Player's attitudes were favourable at baseline, and perhaps there does not need to be a significant change in attitudes for behaviour change as long as attitudes are favourable at the start.

An important measure of the local impact of PEP was eyewear sales and borrowings. All control venues opted to be equipped with the project material after the trial, and the promotion was continuing at the time of writing. The proactive stance taken by the venue staff contributed to the successful running of PEP. From the favourable results, the Victorian Squash Federation is seeking to have all Victorian squash venues set up with the project material. Squash venues need to include protective eyewear as a priority for their safety practices and policies. This, supported by task specific materials promoting behaviour change, is probably the best strategy for widespread use of protective equipment in squash.

In the broader context, sports injury prevention and health promotion research based on ecological models of specific behaviour change should be evaluated through controlled and randomised evaluation frameworks. It is imperative that this research field builds a strong evidence base for interventions and does not rely solely on education efforts without evaluation. Behaviour change is a process, and much further research is required to understand this as it applies to the sports injury prevention domain. Our PEP was successful in that players exposed to PEP changed their behaviours, and the sales of eyewear during the trial increased significantly. The true success will be the sustainability and dissemination of the project and favourable eyewear behaviours, as well as evidence of the prevention of eye injuries long into the future.
This project was awarded a Victoria-wide Sport and Recreation Industry award because of its significant contribution to the safety of community sport.

\section{ACKNOWLEDGEMENTS}

This study was funded by an NHMRC Translational Grant in Injury. RE was funded by an NHMRC Public Health Postgraduate Research Scholarship. CF was supported by an NHMRC Principal Research Fellowship. We thank Paul Vear, Executive Director, Victorian Squash Federation, for his contribution to this project.

\section{Authors' affiliations}

R Eime, R Wolfe, Department of Epidemiology and Preventive Medicine, Monash University, Melbourne, Australia

C Finch, NSW Injury Risk Management Research Centre, University of New South Wales, Sydney, Australia

N Owen, Cancer Prevention Research Centre, School of Population

Health, University of Queensland, Brisbane, Australia

C McCarty, Marshfield Medical Research Foundation, Marshfield,

Wisconsin, USA

Competing interests: none declared

\section{REFERENCES}

1 Finch C, McGrath A. A national sports safety framework. ASIP Taskforce, ed. Canberra: Australian Sports Commission, 1997:60.

2 van Mechelen W. Sports injury surveillance systems. Sports Med 1997;24:164-8.

3 Finch C. Why is sports-injury prevention not progressing? Int I Sports Med 2001;2:1-3.

4 Finch C. An overview of some definitional issues for sports injury surveillance. Sports Med 1997; 24:157-63.

5 Janda D. Sports injury surveillance has everything to do with sports medicine. Sports Med 1997;24:169-71.

6 Eime RM, Finch CF, Sherman CF, et al. Are squash players protecting their eyes? Inj Prev 2002;8:239-241.

7 Eime RM, Finch CF. Have the attitudes of Australian squash players towards protective eyewear changed over the past decade? Br J Sports Med 2002;36:442-5.

8 Eime R, Zazryn T, Finch C. Epidemiology of squash injuries requiring hospital treatment. Inj Control Saf Promot 2003;10:243-5.

9 Gallaway M, Aimino J, Scheiman M. The effect of protective sports eyewear on peripheral visual field and a peripheral visual performance task. J Am Optom Assoc 1986;57:304-10.

10 International Federation of Sports Medicine. Eye injuries and eye protection in sports. National Strength and Conditioning Association Journal 1990;12:42-3.

11 Vinger P. A practical guide for sports eye protection. Phys Sportsmed 2000;28:1-13.

12 Silko GJ, Cullen PT. Indoor racquet sports injuries. Am Fam Physician 1994;50:374-80

13 Erie JC. Eye injuries, prevention, evaluation, and treatment. Phys Sportsmed 1991;19:108-22.

14 Pashby T. Saving sight in sport. Available from: http://www. whalers.org/ fairplay/pashby/sight94/sight.htm, Accessed 18 January, 2004.

15 Eime R, Owen N, Finch C. Protective eyewear promotion: ecological principles of health behaviour in the design of a sports injury prevention program. Sports Med 2004;34:629-38.

16 Squash Australia. Protective eyewear policy. Synergy 1998:32-3.

17 Eime R, McCarty C, Finch C, et al. Unprotected eyes in squash: not seeing the risk of injury. J Sci Med Sport 2005;8:92-100.

18 Donner A, Klar N. Design and analysis of cluster randomisation trials in health research. London: Arnold, 2000.

19 Stata. Stata statistical soffware release 8.0. College Station, Texas: Stata Corporation, 2003.

20 Perry MJ, Marbella A, Layde PM. Association of pesticide safety beliefs and intentions with behaviors among farm pesticide applicators. Am J Health Promot 1999;14:18-21.

21 Michaud P, Renaud A, Narring F. Sports activities related to injuries? A survey among 9-19 year olds in Switzerland. Inj Prev 2001;1:41-5.

22 Geller E. The psychology of safety - how to improve behaviors and attitudes on the job. Boca Raton: CRC Press, 1998:390.

23 Sallis J, Owen N. Ecological models of health behavior. In: Glanz K, Rimer B, Lewis F, eds. Health behavior and health education. Theory, research, and practice. San Fransisco: Jossey Bass, 2002:462-85.

24 International Federation of Sports Medicine. Eye injuries and eye protectors in sports. Athletic Therapy Today, 1999;4:6-8. 